METALLURGY AND FOUNDRY ENGINEERING - Vol. 37, 2011, No. 1

\author{
Magdalena Kawalec*, Edward Fraś**
}

\title{
FORMING OF THE MICROSTRUCTURE IN Fe-C-V ALLOYS
}

\section{INTRODUCTION}

Owing to its beneficial technological and mechanical properties, cast iron not only continues being the most widely used cast alloy but is also the material under constant development. Cast iron is used in nearly every branch of the industry. Because of the growing requirements from users of this material, new grades of cast iron of better mechanical and performance properties are searched. One of the lines in this search is connected with introduction to cast iron of alloying elements, which change the type of matrix and the morphological characteristics of graphite, or promote the crystallisation of carbides. The element of very interesting, though still not fully explored, properties is vanadium. Literature on cast iron with high vanadium content is also very scarce. In [1, 2], information on the structure of $\mathrm{Fe}-12.9 \% \mathrm{~V}-2.94 \% \mathrm{C}$ alloys was given. In these alloys, the presence of fibrous $\gamma+\mathrm{VC}_{1-\mathrm{x}}$ eutectic was observed with volume content of vanadium carbide amounting to about $20 \%$. The results of microstructural examinations of $\mathrm{Fe}-\mathrm{C}-\mathrm{V}$ alloys with carbon content in the range of $1.38 \div 4.16 \%$ and vanadium content in the range of $6.7 \div 15.5 \%$ as well as information on mechanical and tribological properties of these alloys are given in [3, 4]. The main source of information on the interaction of alloying constituents and their distribution in individual phases forming a system are phase equilibrium diagrams. However, the degree of difficulty and the cost of making such diagrams increase drastically with the increasing number of constituents included in the system [5]. There are several items in literature that describe the Fe-C-V phase equilibrium diagrams $[6,7,8,9]$, but they are not fully consistent with the metallographic practice. Hence follows the objective of the present studies involving manufacture of the Fe-V-C alloys characterised by different chemical composition with subsequent analysis of their microstructure. The paper focusses on alloys with near-eutectic chemical composition.

* Ph.D., ** Prof., Ph.D., D.Sc.: Faculty of Foundry Engineering, AGH University of Science and Technology, Kraków, Poland; e-mail: kawalec@agh.edu.pl 


\section{METHODOLOGY OF RESEARCH}

To conduct the planned investigations, a series of melts with variable content of carbon and vanadium was made in a Balzers type vacuum furnace in the atmosphere of argon. The following materials were used: Fe-V master alloys containing $81.7 \%$ vanadium, armco iron, and technically pure graphite. Moulds made from molochite flour based on sodium silicate hardened with $\mathrm{CO}_{2}$ were preheated up to a temperature of $550{ }^{\circ} \mathrm{C}$, and poured next with molten iron at a temperature of $1600{ }^{\circ} \mathrm{C}$. From the knocked out castings, specimens for metallographic examinations were cut out.

Unetched specimens were examined under LEICA MEF4 M optical microscope and JEOL 5500LV scanning microscope with secondary electrons. This enabled differentiating between vanadium carbides and other phases, which was not always possible when optical microscope was the only tool used in investigations. For more detailed examination of the geometry of individual phases, the specimens were deep etched with aqua regia and examined under scanning microscope. The percent content of structural constituents was determined on a LEICA QWin automatic image analyser.

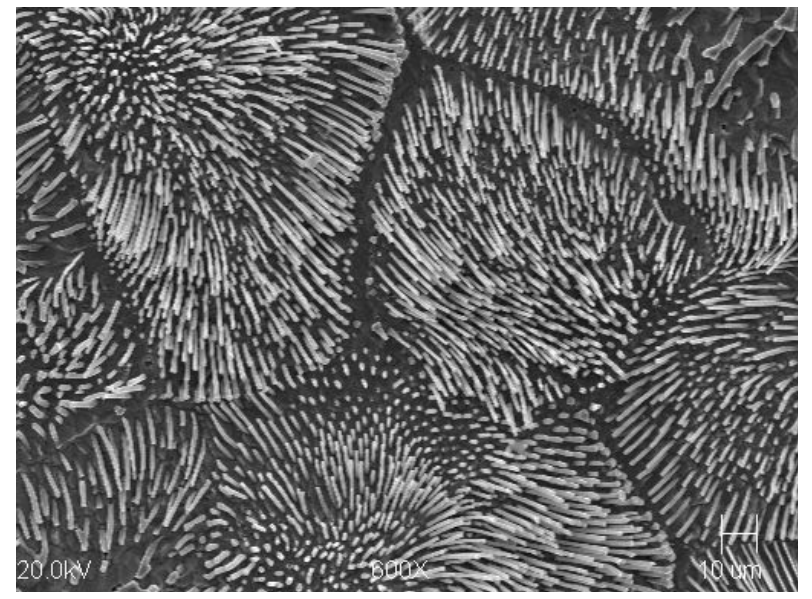

Fig. 1. Microstructure of near-eutectic Fe-C-V alloy after deep etching with aqua regia

\section{DISCUSSION OF RESULTS}

Table 1 compares the chemical composition of the examined alloys, their microstructure and content of structural constituents. Besides vanadium eutectic, depending on $C / V$ ratio in cast iron (where: $C, V$ - carbon and vanadium content in alloy in $\%$, respectively), the following microstructural constituents were observed to occur:

- alloyed ferrite (Fig. 2a), when the value of $C / V$ was $0.10 \div 0.13$,

- granular pearlite (Fig. 2b), when the value of $C / V$ was 0.15 ,

- lamellar pearlite (Fig. 2c), when the value of $C / V$ was $0.24 \div 0.30$. 
Table 1. Chemical composition and percent content of structural constituents in Fe-C-V alloys

\begin{tabular}{|c|c|c|c|c|c|c|c|c|}
\hline \multirow{2}{*}{ Melt No. } & \multicolumn{2}{|c|}{$\begin{array}{l}\text { Chemical } \\
\text { composition }\end{array}$} & \multicolumn{3}{|c|}{ Matrix constituent content } & \multirow{2}{*}{$\begin{array}{l}f_{w} \\
{[\%]}\end{array}$} & \multirow{2}{*}{$C / V$} & \multirow{2}{*}{$S_{c}$} \\
\hline & $\begin{array}{c}\mathrm{C} \\
{[\%]}\end{array}$ & $\begin{array}{l}\mathrm{V} \\
{[\%]}\end{array}$ & $\begin{array}{l}f_{f} \\
{[\%]}\end{array}$ & $\begin{array}{l}f_{p . z .} \\
{[\%]}\end{array}$ & $\begin{array}{l}f_{p . p .} \\
{[\%]}\end{array}$ & & & \\
\hline 1 & 1.45 & 15.08 & 73.59 & - & - & 26.41 & 0.10 & 1.02 \\
\hline 2 & 1.60 & 12.60 & 76.00 & - & - & 24.00 & 0.13 & 1.00 \\
\hline 3 & 1.70 & 11.37 & - & 79.3 & - & 20.70 & 0.15 & 1.00 \\
\hline 4 & 1.68 & 11.16 & - & 79.6 & - & 20.40 & 0.15 & 0.98 \\
\hline 5 & 2.03 & 8.50 & - & - & 81.42 & 16.35 & 0.24 & 1.00 \\
\hline 6 & 2.18 & 7.67 & - & - & 83.65 & 18.58 & 0.28 & 1.01 \\
\hline 7 & 2.23 & 7.33 & - & - & 86.68 & 13.32 & 0.30 & 1.00 \\
\hline \multicolumn{4}{|c|}{$\begin{array}{l}f_{f}-\text { ferrite content in cast iron } \\
f_{p . z .}-\text { granular pearlite content in cast iron }\end{array}$} & \multicolumn{5}{|c|}{$\begin{array}{l}f_{p . p .}-\text { lamellar pearlite content in cast iron } \\
f_{w}-\text { eutectic carbides content in cast iron }\end{array}$} \\
\hline
\end{tabular}

Deep etching with aqua regia and observations under scanning microscope revealed in the grains of regular eutectic (Figs. 1 and 3a), a continuous, ramified skeleton of vanadium carbide growing out from one common centre (Fig. 3b, c). It is also worth noting that, at the final stage of growth, some fibres have been transformed into lamellar forms (Fig. 3a, b).

A relationship between the content of carbon and vanadium corresponding to a neareutectic structure (eutectic line, Fig. 4a) is described with the following equation of regression:

$$
C_{e}=7.618 \cdot V_{e}^{-0.617}
$$

where: $C_{e}$ and $V_{e}$ - carbon and vanadium content in eutectic in \%, respectively.

The coefficient of correlation in this equation assumes a very high value of $R=0.99$.

The degree of eutectic saturation $S_{c}$ is a quotient of carbon content in alloy $C$ divided by the carbon content in eutectic $C_{e}$. Considering the above and equation (1), the degree of eutectic saturation in Fe-C-V alloys can be expressed with the following formula:

$$
S_{c}=\frac{C}{C_{e}}=\frac{C}{7.618 \cdot V_{e}^{-0.617}}
$$

For $S_{c}<1, S_{c}=1$ and $S_{c}>1$ the alloys of, respectively, hypoeutectic, eutectic and hypereutectic composition are obtained. 
a)

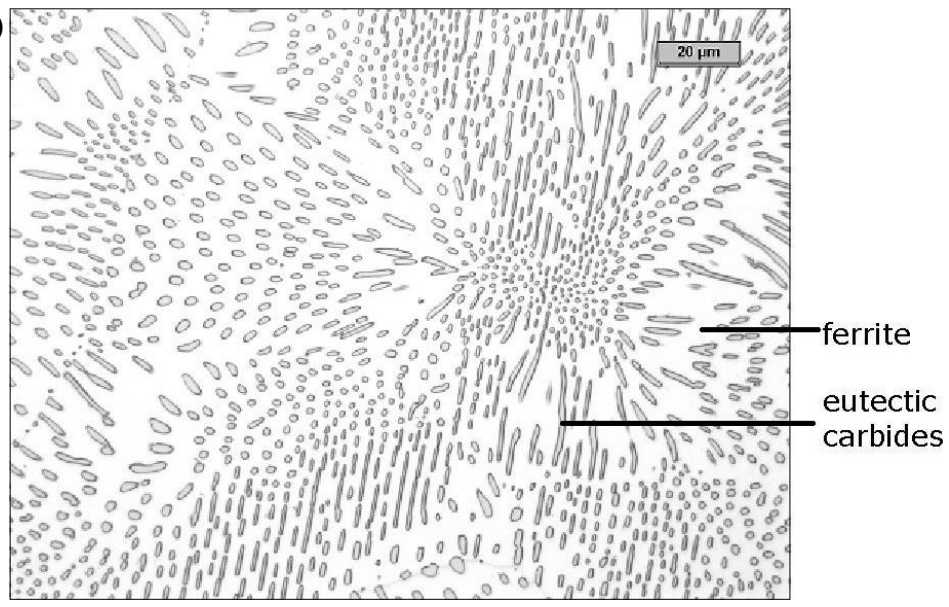

b)

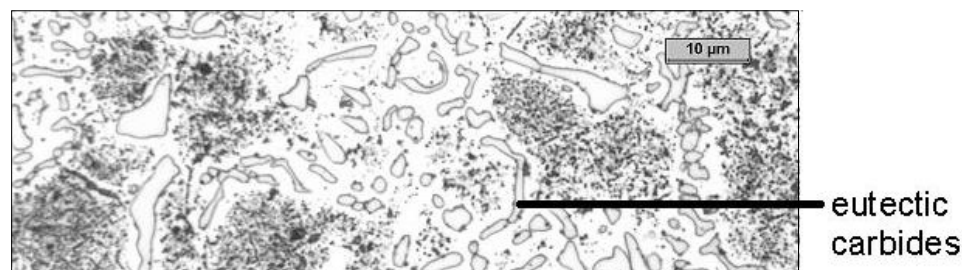

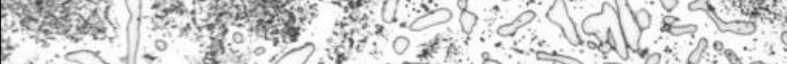

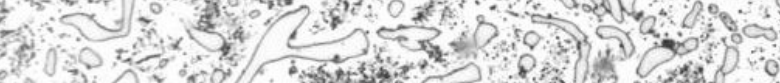

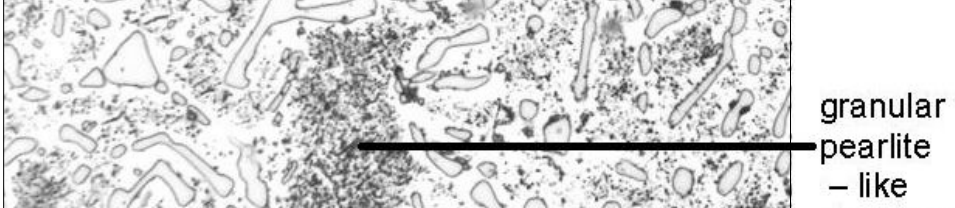

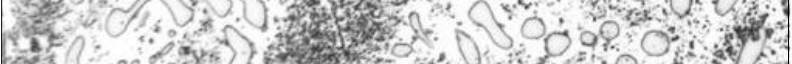

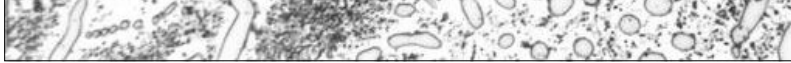
structure

c)

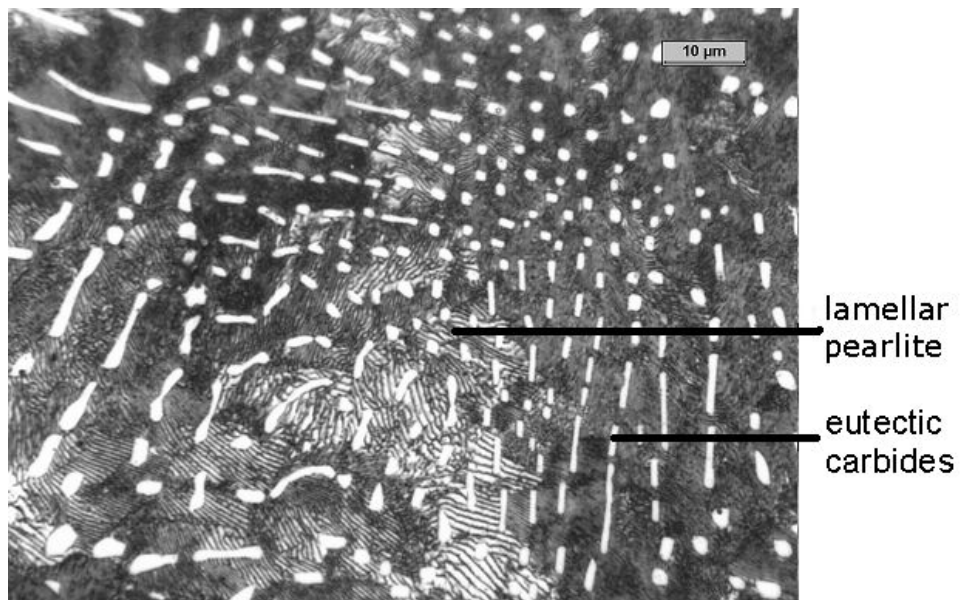

Fig. 2. Microstructure of near-eutectic Fe-C-V alloy 
a)

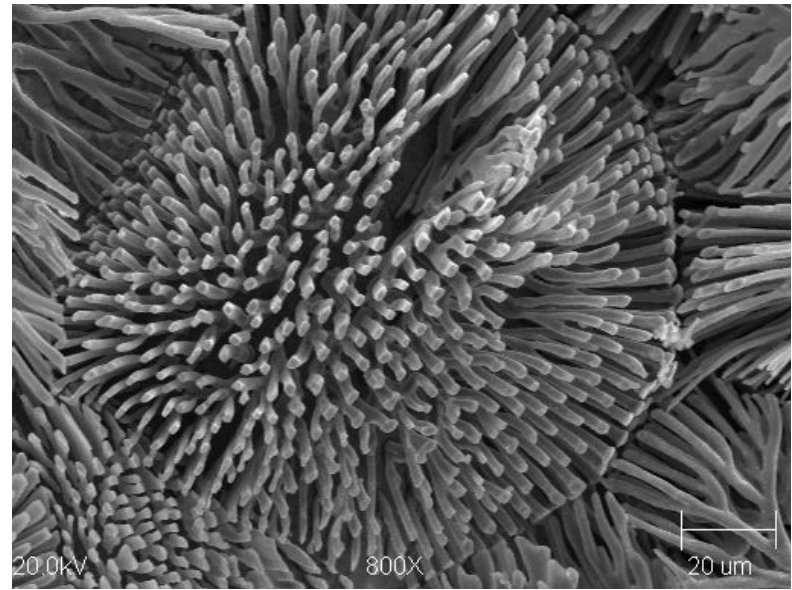

b)

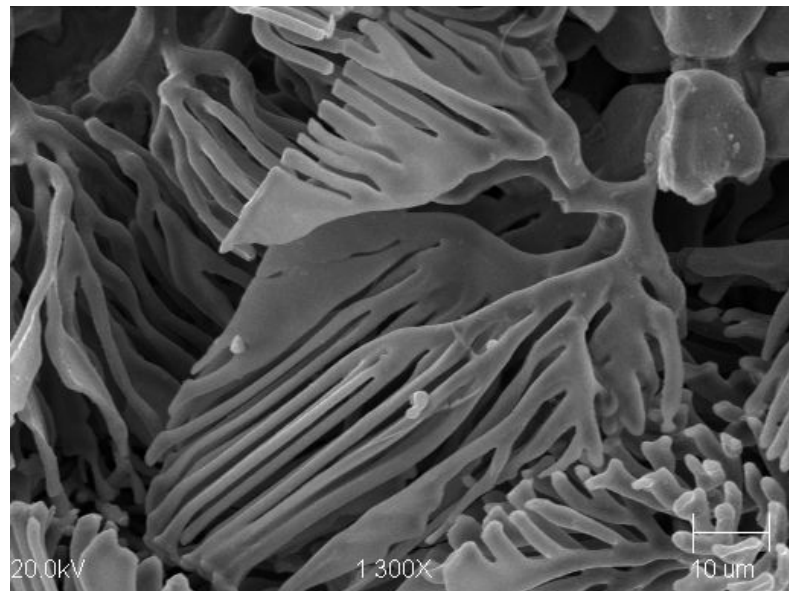

c)

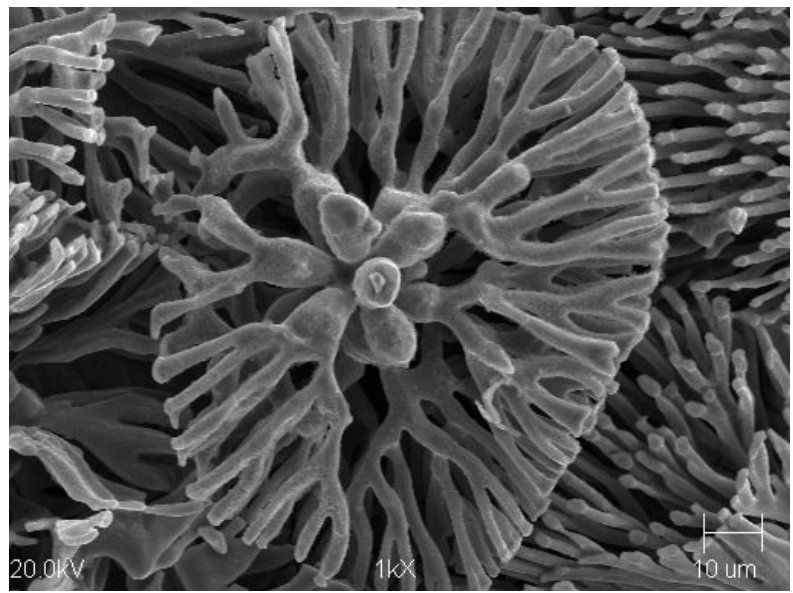

Fig. 3. Examples of the ramified vanadium carbide present in eutectic grains 
a)

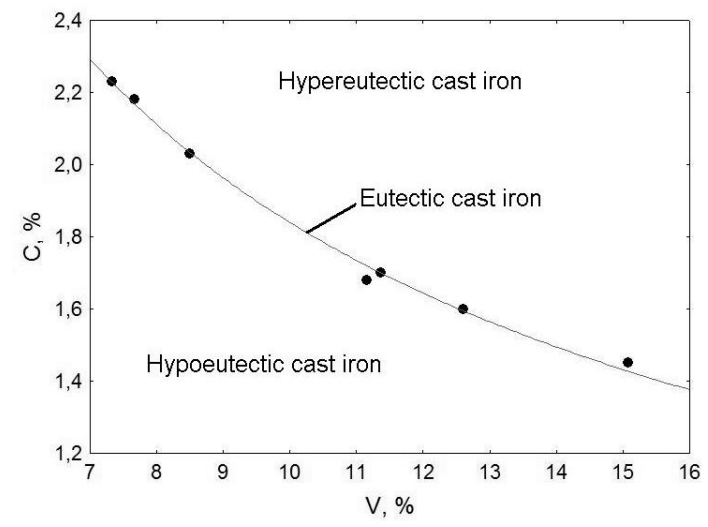

b)

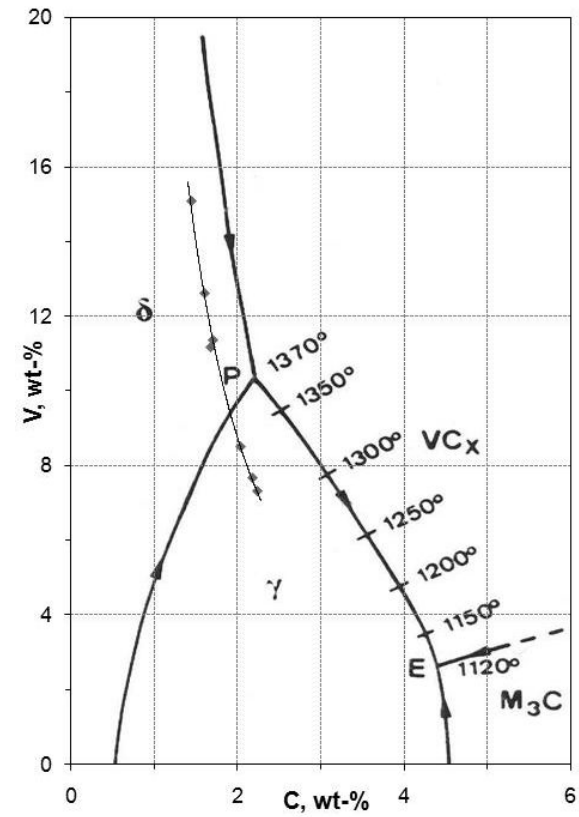

Fig. 4. The run of eutectic line in Fe-C-V alloys (a) and (b) projection of eutectic line (equation (1)) against the background of $\mathrm{Fe}-\mathrm{C}-\mathrm{V}$ system described in [6]

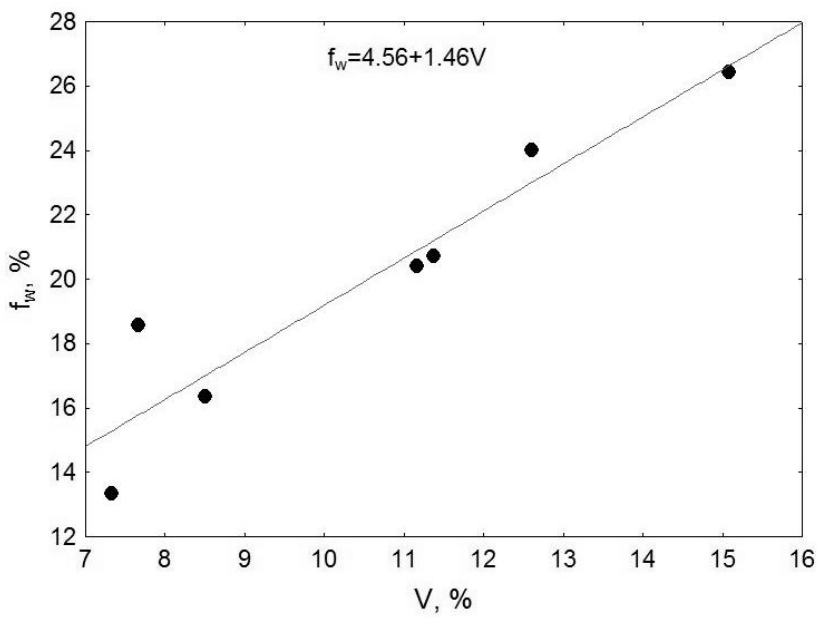

Fig. 5. Effect of vanadium content on the content of eutectic carbides $\left(f_{w}\right)$ in near-eutectic alloys

Figure 5 shows the effect of vanadium and eutectic saturation degree $S_{c}$ on the content of vanadium carbides $f_{w}$, wherefrom it follows that increasing content of vanadium in neareutectic alloys increases the content of vanadium carbide eutectic. 
Figure $4 \mathrm{~b}$ shows eutectic line plotted as a result of the carried out research, visible against the background of $\mathrm{Fe}-\mathrm{C}-\mathrm{V}$ alloy phase equilibrium diagram [6]. From this drawing it follows that the experimentally plotted eutectic line is shifted to the left in respect of the eutectic line in phase equilibrium diagram.

An example of the cooling curve for high-vanadium eutectic cast iron and a differential curve are shown in Figure 6.

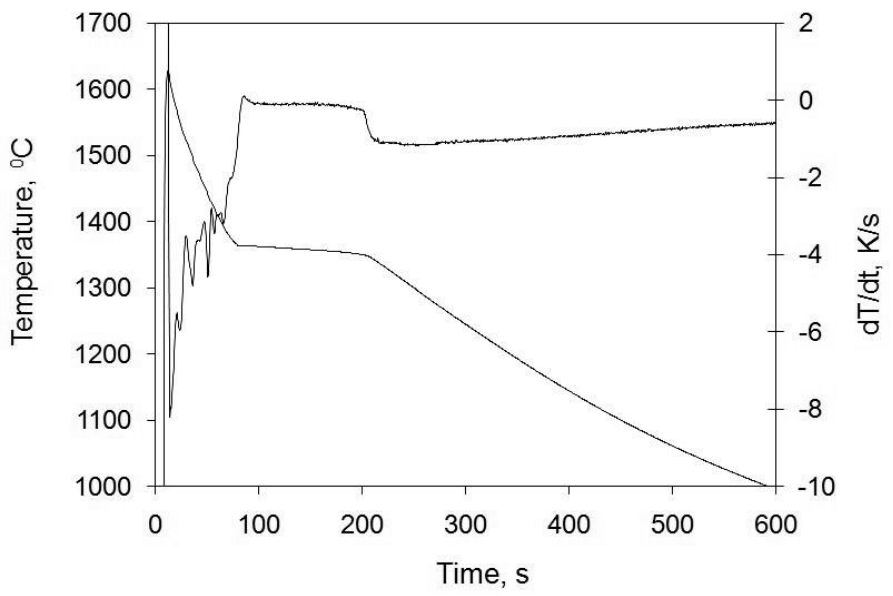

Fig. 6. Cooling curve and its derivative plotted for eutectic high-vanadium cast iron

\section{CONCLUSIONS}

In near-eutectic alloys containing from 1.45 to $2.23 \% \mathrm{C}$ and from 7.33 to $15.08 \% \mathrm{~V}$, depending on the value of the $C / V$ ratio, besides vanadium eutectic, the following microstructural constituents are present:

- alloyed ferrite, when the value of $C / V$ is $0.10 \div 0.13$,

- granular pearlite, when the value of $C / V$ is 0.15 ,

- lamellar pearlite, when the value of $C / V$ is $0.24 \div 0.30$.

The derived relationship showing the eutectic saturation ratio enables easy determination if the examined Fe-C-V alloy is of hypoeutectic, eutectic or hypereutectic type, using only the results of chemical analysis, without the need for troublesome and time consuming metallographic examinations.

The eutectic line determined experimentally is shifted to the left respective of the eutectic line present in phase equilibrium diagram.

Increasing the content of vanadium in near-eutectic alloys increases the content of vanadium carbide eutectic.

\section{Acknowledgements}

The work was supported by Project No. 10.10.170.396 


\section{REFERENCES}

[1] Fraś E., Guzik E.: Pierwotna mikrostruktura stopów Fe-C-V, Archiwum Hutnictwa, 25 (1980) 4, 757-772

[2] Fraś E.: Krystalizacja metali, WNT, Warszawa, 2003

[3] Kawalec M., Fraś E.: Structure, Mechanical Properties and Wear Resistance of Highvanadium Cast Iron, ISIJ International, 48 (2008) 4, 518-524

[4] Fraś E., Kawalec M.: Struktura, właściwości mechaniczne i odporność na zużycie ścierne stopów Fe-C-V, Inżynieria Materiałowa, 29 (2008) 2, 78-85

[5] Kaczyński J., Prowans S.: Podstawy teoretyczne metaloznawstwa, Wyd. Śląsk, Katowice 1972

[6] Kesri R., Durand-Charre M.: Metallurgical structure and phase diagram of Fe-C-V system: comparison with other systems forming MC carbides, Materials Science and Technology, 4 (1988) 4

[7] Collins M.J.: Fe-V-C phase diagram, Journal of the Iron and Steel Institute, 210 (1972) 284

[8] Dmitrieva G.P., Shurin A.K., Vasilev A.D.: Mechanicostructural properties of iron alloys with vanadium carbide, Metal Science and Heat treatment of Metals, 4 (1978) 325-327

[9] Frey H., Holleck H.: DTA investigations of high temperature phase equilibria in ternary transition metalcarbon system, Thermal Analysis Proceedings of the International Conference, 1 (1975) 339-348

Received

January 2011 